\title{
UMA SÍlABA REBELDE NO CORAÇÃO DO IMPÉRIO: TENSÕES POLÍTICAS E DE GÊNERO NO PRINCIPADO DE DOMICIANO
}

A Rebel Syllable in the Heart of the Empire: Political and Gender Tensions in Domitian's Principate 


\title{
RESUMO
}

O objetivo deste artigo é evidenciar as tensões políticas e de gênero durante o principado de Domiciano (81-96 d.C.) por meio das representações do eunuco Earino construídas nos poemas de Estácio e Marcial. Mais especificamente, buscou-se, com o auxílio dos estudos de gênero e queer, analisar essa figura emblemática que serviu para a construção de imagens acerca das medidas empreendidas pelo imperador Domiciano tanto no campo político quanto no literário, bem como nas regulações de gênero e sexualidade. Dessa forma, percebeu-se que as tensões políticas e de gênero que rondavam a corte domiciana estavam entrelaçadas e buscavam, na representação de uma identidade rebelde, não fixa ou homogênea, reforçar performances de gênero.

\section{PALAVRAS-CHAVE}

Gênero. Eunucos. Literatura.

\begin{abstract}
The aim of this article is to highlight the political and gender tensions during Domitian's principate (8196 AD) through the representations of the eunuch Earinus created in poems by Statius and Martial. More specifically, we sought, based on gender and queer studies, to analyse this emblematic figure that helped the construction of images of the measures taken by the Domitian emperor, both in the political and literary fields, as well as in the ambit of gender and sexuality regulations. Hence, it was perceived that the political and gender tensions that surrounded Domitian's court were intertwined and sought to reinforce gender performances through the representation of a rebellious, not fixed or homogeneous identity.
\end{abstract}

\section{KEYWORDS}

Gender. Eunuchs. Literature. 
$\mathbf{A}$ literatura sempre foi uma fonte profícua para o estudo da história da Antiguidade Clássica romana. Mesmo em momentos nos quais a disciplina histórica se afastou da literatura em busca de modelos explicativos próximos aos das ciências duras, priorizando a busca pela verdade em vestígios do passado e colocando os documentos literários no campo da fantasia e da imaginação, terrenos antagônicos ao que era considerado a realidade, a história antiga nunca abriu mão de tais testemunhos para compreender o passado, uma vez que o especialista nessa área não contava com outros documentos além de dados arqueológicos e algumas atas do Senado romano (GUARINELLO, 2013).

A literatura, utilizada em inúmeros estudos sobre temas tradicionais da história de Roma, como a política e a religião, também se mostra fonte frutífera para entender as relações sociais e os costumes romanos, bem como representações e práticas sexuais e de gênero. Neste artigo, buscam-se as conexões que a literatura pode estabelecer entre os terrenos tradicionalmente vistos como separados da política e das relações de gênero.

Entende-se que, pelas reflexões tecidas a seguir, a literatura se tornou ferramenta importante na política imperial de Domiciano e transformou questões delicadas, como seu possível relacionamento com o garoto Earino, em fontes de divulgação de sua própria administração e governo. Gênero, sexualidade, propaganda política e manutenção do império são amalgamados pelas linhas escritas pelos poetas Marcial e Estácio, e um dos elementos centrais desse amálgama é o eunuco Earino.

Segundo as informações literárias, o garoto foi escravo de Domiciano. É provável que o imperador tenha castrado Earino e o empregado na sua corte como copeiro, mantendo com ele relações eróticas e afetivas. Trataremos aqui de representações, construções discursivas que não necessariamente narram eventos que de fato ocorreram. Estácio, no poema 4 do seu terceiro livro d'As Silvas, "Capilli Flavi Earini", ${ }^{1}$ e Marcial, em alguns poemas do seu nono livro de epigramas (11, 12, $13,16,17$ e 36), foram os escritores latinos que mais construíram representações acerca do eunuco Earino.

Há também uma ligeira referência a Earino na História de Roma, de Dion Cássio, quando explica por que Domiciano teria proibido, entre 82 e 83 d.C, a castração de homens no território do império romano. Para Dion Cássio, tratava-se apenas de uma provocação de Domiciano ao irmão Tito, imperador que o antecedeu e que era muito afeito aos eunucos (Dión Cássio, História de Roma, 67 2.3).

As obras de Estácio e Marcial são importantes para estudar não apenas eventos ligados a Earino, mas, do mesmo modo, questões relacionadas à corte imperial domiciana, às práticas político-ideológicas de seu principado e a tensões e papéis de gênero que a cercavam. Pretende-se refletir sobre as representações construídas pelos dois poetas sobre Earino, seu corpo e sua castração, considerando também como tais representações criam uma imagem com significados diversos e, por vezes, contraditórios acerca dos eunucos, da corte imperial e das identidades de gênero em voga no referido período.

\footnotetext{
${ }^{1}$ Este título não é original. Não se sabe o título que Estácio teria atribuído ao poema nem se o autor o fez. O título aqui mencionado foi atribuído por algum copista medieval desconhecido e, em tradução livre, pode ser lido em português como Os cabelos de Earino.
} 
As obras de Estácio, Marcial e Dion Cássio são as únicas que trazem dados sobre uma possível narrativa acerca de Earino. Enfrentando tal biografia por meio de construções literárias, as informações sobre a origem do garoto, sua castração, idade e relações com Domiciano são viáveis de reconstrução, ainda que de forma bastante fragmentada. Por isso, acredita-se que, durante a análise dos textos clássicos, esses dados biográficos serão esclarecidos.

Os seis epigramas de Marcial sobre Earino dissertam sobre três assuntos: 9.11, 9.12 e 9.13 celebram o nome do eunuco; 9.16 e 9.17 narram a oferta e o envio dos cabelos de Earino ao templo de Esculápio, em Pérgamo; e, em 9.36, o garoto e Domiciano são comparados àqueles que seriam seus correspondentes celestiais: Ganimedes e Júpiter, respectivamente.

Os cinco primeiros epigramas teriam sido apresentados a Earino e a Domiciano em forma de libelo. Somente o 9.36 não teria sido mostrado ao imperador e ao eunuco, sendo inserido no livro 9 apenas quando Marcial o organizou para publicação, na década de 90 d.C. (HENRIKSÉN, 1998).

As Silvas 3.4 também trabalha quase com os mesmos temas que Marcial abordou nos seus epigramas, tendo sido publicada no mesmo período, entre 92 e 95 d.C. De acordo com estudiosos como David Vessey (1973) e Gabriel Laguna Mariscal (1992), o poema de Estácio pode ser dividido em três partes, cada uma delas com assuntos específicos e transições entre tempo e espaço.

A primeira parte acontece em Roma, no tempo presente, e compreende os versos 1 a 20, nos quais Estácio faz três invocações: a primeira sobre o cabelo de Earino (1-5), a segunda sobre o deus Esculápio (6-11) e a última a respeito de Pérgamo, terra natal de Earino (12-20). Esse "prefácio" ainda termina com uma grande referência enaltecedora de Domiciano.

Na segunda parte do poema (versos 21 a 77), Estácio faz um tipo de descrição etiológica. Desloca-se para o passado a fim de narrar a trajetória de Earino, desde quando é encontrado por Vênus em Pérgamo (21-46), trazido por ela para Roma e introduzido no palácio de Domiciano (46-64), até sua emasculação, feita por Esculápio e auxiliada por Vênus (65-77).

A última parte da narrativa (versos 78 a 106) retorna ao presente e à cidade de Roma. É nesse trecho que acontece o corte dos cabelos do puer e o envio ao templo de Esculápio em Pérgamo (78-98), finalizando o poema com uma prece de Earino a Esculápio para que conceda eterna juventude a Domiciano (99-106).

Laguna Mariscal afirma que essa estrutura é uma técnica comumente usada em todo o decorrer d'As Silvas, nas quais o início e o fim dos poemas versam sobre temas contemporâneos e o trecho central faz uma digressão ao passado em forma de relato etiológico e mitológico: "Remonta ao passado e se caracteriza por um importante componente fantástico, frente a certo realismo da descrição do presente" (1992, p. 306).

As páginas d'As Silvas indicam que foi o próprio Earino que encomendou o poema para Estácio:

Além disso, Earino, liberto de nosso Domiciano, sabe quanto tempo eu adiei o pedido dele, quando ele me pediu para dedicar em versos o cabelo que ele estava enviando a Esculápio em 
Pérgamo juntamente com uma caixa decorada com joias e um espelho (Estácio, As Silvas, 3.pref. 17-20). ${ }^{2}$

Em contrapartida, não se tem nenhuma informação sobre se Marcial recebeu algum pedido desse tipo para escrever seus epigramas. Henriksén (1997) afirma que há a possibilidade de Earino ter pedido obras a ambos os poetas, mas também Marcial poderia ter se sentido compelido a escrever os poemas sobre o eunuco quando descobriu que Estácio estava escrevendo o poema dele. Isso parece provável, já que escrever sobre o relacionamento entre o garoto e Domiciano seria uma grande oportunidade de bajular o imperador, seja pelo pedido do puer, seja por iniciativa própria. Assim, o epigramatista poderia ter visto nesse evento a oportunidade de compor alguns versos e se aproximar dos acontecimentos do palácio e da família imperial.

Como Caroline Vout (2007) afirma, o prefácio do terceiro livro das Silvas sugere que o poema é destinado tanto a Domiciano e sua atuação como imperador quanto a Earino, pois a motivação para a escrita seria inspirada nos dois. Vout também defende que os epigramas de Marcial seguem a mesma proposta: elogiar o puer delicatus do princeps era uma forma de elogiar o próprio princeps. Assim, "se a oferta de Earino foi tão notável quanto podemos imaginar, logo, parece provável que os poetas contemporâneos colaborariam espontaneamente para celebrá-lo" (HENRIKSÉN, 1997, p. 292).

A análise que se segue procura entender como essa literatura, financiada pelo próprio Domiciano, colaborou para narrar e enaltecer seu governo, valendo-se de recursos para apaziguar as possíveis tensões políticas que a relação entre o eunuco e o imperador pudesse acarretar. Assim, tais tensões, ao mesmo tempo que as contradizem, se retroalimentam das relações de gênero estabelecidas pela aristocracia romana e pela corte domiciana - são usadas por Estácio e Marcial com o intuito de elaborar e propagar o que Carole Newlands chamou de ideologia imperial (NEWLANDS, 2002). ${ }^{3}$

Antes de adentrar a análise, um esclarecimento se faz necessário: o conceito de gênero aqui utilizado se afina com as formulações dos estudos queer, em especial aquelas encontradas nas obras de Judith Butler (2001, 2003, 2014). Dessa forma, gênero é entendido como performance, ou seja, atos e discursos que reificam regras reguladoras sobre o comportamento, os corpos e as identidades sexuais. Logo, numa perspectiva queer, não é possível alguém pertencer a um gênero ou ter guardada dentro de si uma identidade de gênero. O gênero é o próprio aparato de poder que regula as relações entre indivíduos, suas identidades e seus corpos.

Nessa esteira, um olhar queer sobre a Antiguidade romana buscaria reconhecer performatividades ou regulações de gênero em uma ordem cultural que produzia efeitos de coerência e continuidade entre as noções de sexo (anatômico, homem

\footnotetext{
${ }^{2}$ No original: "Earino praeterea, Germanici nostri libertus, scit quam diu desiderium eius moratus sim, cum petisset ut capillos suos, quos cum gemmala pyxide et speculo ad Permenum Asclepium mittebat, versibus dedicarem." A tradução do prefácio do terceiro livro d'As Silvas, bem como do poema 3.4, foi feita pelo autor deste artigo com base na versão editada e traduzida do latim para o inglês por D.R. Shackleton Bayle, publicada em 2003. A tradução se deu por meio da comparação com o original em latim. Todos os epigramas de Marcial citados aqui em língua portuguesa foram retirados de MARCIAL, 2001.

${ }^{3} \mathrm{O}$ conceito de ideologia imperial, como Newlands o entende, será esclarecido adiante, assim que se mostrar necessário.
} 
ou mulher), gênero (masculino ou feminino), sexualidade (hétero ou homossexual) ${ }^{4}$ e prática sexual (ativo ou passivo). Mais interessante do que isso, seria olhar para os sujeitos que tenham potencial de provocar tensões nesse sistema de discursos e práticas reguladoras, expondo sua fabricação discursiva e histórica como algo coerente. Parece que o eunuco Earino tem esse potencial, como se mostrará a seguir.

\section{ENTRE-LUGARES NOS TEXTOS, CORPOS NO ENTRE- -LUGAR: A REPRESENTAÇÃO DE EARINO}

Estácio e Marcial se preocuparam com a seleção de termos e expressões que podem nos ajudar a compreender o olhar da sociedade romana acerca do corpo dos eunucos e os problemas de gênero que carregam. Entretanto, as imagens de Earino apresentam características muito diferentes das representações mais comuns sobre os castrados romanos. Marcial, por exemplo, utiliza a figura dos eunucos para desqualificar comportamentos e personagens por ele descritos. ${ }^{5}$

Caroline Vout acrescenta que, por diversas vezes, os eunucos eram considerados criaturas hediondas (2007). Escrever sobre o puer delicatus de Domiciano, sendo ele castrado ou não, implica lidar com um assunto espinhoso: não poder fazer as críticas que tais escritores achavam cabíveis ao garoto. Em se tratando de Estácio e Marcial, isso era ainda mais emblemático porque eles dependiam de suas poesias para sobreviver, muitas delas encomendadas pelo próprio imperador (CITRONI et al., 2006). Contudo, não deixaram de escrever, como puderam, seus versos mordazes sobre a relação entre o princeps e o garoto.

As tensões de gênero acerca de Earino e seu corpo foram um tema comum para os dois autores-fonte. Algumas palavras usadas por Estácio e por Marcial podem explicar melhor tais tensões. Nos epigramas 9.11-13, as ambiguidades de gênero aparecem. Neles, há elogio ao nome de Earino, baseado na proximidade do nome do menino com termo grego ear (દ̌ar) e sua transliteração para o latim como verna (em português, primavera). Eis o primeiro epigrama:

O nome, com violetas e rosas nascido, com que se nomeia do ano a melhor parte, que tem o sabor do Hibla e de áticas flores, que tem o odor do ninho da ave soberana; nome mais doce que o néctar divino, apelido que mais quereria o efebo de Cíbele e o que faz a mistura nas taças do Tonante,

\footnotetext{
${ }^{4}$ Aqui é preciso salientar que os conceitos de hétero e homossexualidade, bem como de sexualidade, não têm valor epistemológico para compreender relações, representações e práticas sexuais anteriores ao século XIX, como já evidenciado por Michel Foucault (1988). De acordo com Paul Veyne (2008), os conceitos de passividade e atividade seriam mais adequados para pensar as relações sexo-afetivas tanto entre pessoas do mesmo sexo quanto entre homens e mulheres na Antiguidade greco-romana. Desse modo, ao adequar as reflexões queer para o passado romano, seria mais frutífero eliminar desse esquema a categoria de sexualidade e analisar as regulações de gênero apenas com base na tríade sexo, gênero e prática sexual.

${ }^{5}$ É o que pode ser percebido nos epigramas $2.45 ; 2.86 ; 3.24 ; 3.71,3.81 ; 5.41 ; 9.2 ; 11.74 ; 13.63$ e 13.64, para citar apenas alguns.
} 


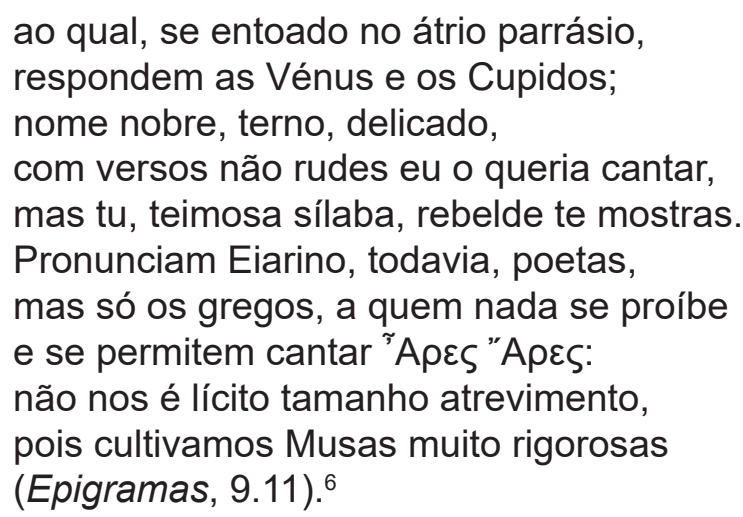

Nesse epigrama, Marcial dá um senso de feminilidade ao nome do eunuco no décimo verso: "nomen nobile, molle, delicatum". Enquanto a palavra nobile (nobre) conecta Earino ao contexto da corte de Domiciano, como aponta Christer Henriksén (1998), molle e delicatum são usados para ligar o puer e seu nome aos estereótipos elitistas de delicadeza e ternura associados à feminilidade ou efeminação, como escreveu Caroline Vout (2007).

De acordo com Craig A. Williams (2010), termos como molle e mollitia, empregados para descrever um homem nesse contexto literário romano podem sugerir que um indivíduo não é completamente masculino ou que tal masculinidade não atenderia aos requisitos exigidos pelos estratos sociais mais elevados, como seria o caso do círculo de Domiciano.

As Silvas 3.4 também apresentam esses termos. Nos dois primeiros versos do poema Estácio já os usa:
Vá, mecha de cabelo, rápida, eu rogo, através do mar calmo vá, deitado delicadamente sobre a grinalda de ouro, vá! (Estácio, As Silvas, 3.4.1-2, grifo nosso). ${ }^{7}$

No verso em destaque, o autor relata que as mechas de cabelo foram enviadas para Pérgamo acompanhada de joias. Estácio usa, não por acaso, molliter ao lado de auro, o que pode significar duas coisas: por um lado, como defende Gabriel Laguna Mariscal (1992), molliter pode aludir à "moleza" de Earino ou à sua efeminação devido à castração, em contraste com a dureza de auro (ouro); por outro, as duas palavras no mesmo verso sugerem a intensificação da feminilidade do menino, uma vez que auro poderia estar ligado aos ornamentos tradicionalmente associados às mulheres romanas. Também é possível ver a ocorrência das duas palavras no mesmo verso novamente quando Estácio está narrando a viagem de Earino para Roma, acompanhado por Vênus:

\footnotetext{
${ }^{6}$ No original: "Nomen cum violis rosisque natum,/quo pars optima naminatur anni,/Hyblam quod sapit Atticosque flores,/quod nidos olet alitis superbae;/nomen nectare dulcius beato,/quo mallet Cibeles puer vocari/et qui pocula temperat Tonanti,/quod si Parrhasia sones in aula,/respondent Veneres Cupidinesque;/nomen nobile, molle, delicatum/versu dicere non rudi volebam;/sed tu, syllaba contumax,

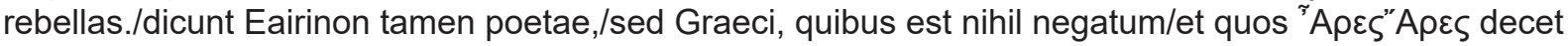
sonare:/nobis non licet esse tam disertis,/qui Musas colimus severiores".

${ }^{7}$ No original: "Ite, comae, facilemque, precor, transcurrite pontum,/ite coronato recubantes molliter auro, ite".
} 
Disse como a Venus dourada estava dirigindo

seus delicados cisnes dos altos de Eryx para os bosques idálicos (Estácio, As Silvas, 3.4.21-22). ${ }^{8}$

Versos depois, Estácio relata a chegada de Earino ao palácio de Domiciano, conduzido por Vênus. O acontecimento é narrado como um casamento, porém fica clara sua vinculação com a efeminação do garoto, sendo ele considerado a noiva do princeps:

ela [Vênus] se aproxima para melhor arrumar os seus cabelos, que vestido seria melhor para acender seu rosto rosado, que ouro é o mais digno em seus dedos e em seu pescoço. Bem, ela conhecia os olhos celestes do líder [Domiciano] ela juntou as tochas de casamento e lhe deu sua noiva generosamente (Estácio, As Silvas, 3.4.50-54). ${ }^{9}$

Como defende Laguna Mariscal, não se pode imaginar que tais descrições se restrinjam só ao acontecimento, mas a escolha das palavras no poema de Estácio intensificam a caracterização de Earino como um indivíduo que confunde, com seu corpo e suas práticas, os papéis de gênero: "molles retoma o motivo da mollitia, recorrente nesta Silva e provavelmente alusivo ao efeminamento de Earino (recorde-se que mulier compartilha da raiz de mollis; e que mollis pode significar 'feminino' em Estácio)" (1992, p. 319, tradução nossa). ${ }^{10}$

Seguindo essa ideia, pode-se entender que a representação de Earino como afeminado se deve à sua castração. Mollire é usado precisamente quando Estácio narra a emasculação do menino: "[...] haud ulli puerum mollire potestas", "a ninguém menos foi confiado o poder de suavizar o rapaz" (Estácio, As Silvas, 3.4.69, grifo nosso). Levando-se em conta as afirmações de Laguna Mariscal (1992) expostas aqui, poder-se-ia traduzir mollire, nesse contexto, como efeminar ou tornar mulher.

Também é possível, porém, que a efeminação de Earino, tanto n'As Silvas quanto em Epigramas, se deva ao seu relacionamento amoroso com Domiciano. O termo puer, geralmente empregado para descrever o garoto que ocupa papel passivo nas relações entre homens, é largamente usado pelos dois autores. Todavia, puer não necessariamente significa amante ou efeminado, mas pode sugerir que o indivíduo em questão era apenas um escravo, tal qual esclarece Williams (2010, p. 83, tradução nossa):

Mas enquanto tais gostos entre os romanos devem ter sido influenciados, em certa medida, por tradições pederásticas gregas, eles devem também ser entendidos no contexto

\footnotetext{
${ }^{8}$ No original: "Dicitur Idalios Erycis de vertice lucos/dum petit et molles agitat Venus aurea cycnos."

${ }^{9}$ No original: "tunc proprior iam cura deae, quae forma capillis/optima, quae vestis roseos accendere vultus/apta, quod in digitis, collo quod dignius aurum./Norat caelestes oculos ducis ipsaque taedas/ iunxerat et plena dederat conubia dextra".

${ }^{10}$ No original: "[...] molles retoma el motivo de la mollitia, recurrente en esta Silva y probablemente alusivo al efeminamiento de Earino (recuérdese que mulier comparte raíz con mollis; y que mollis suele significar 'femenino' en Estacio".
} 
romano de valorização da juventude e dos corpos jovens ligados a uma preferência estética por barbas e rostos macios; afinal de contas, ambos puella ("menina") e puer ("menino") poderiam ser usados para se referir ao objeto sexual de um homem, independentemente da idade dele ou dela, e também ao seu escravo. ${ }^{11}$

Em alguns trechos dos epigramas de Marcial e d'As Silvas, porém, é comum ver a imagem de Earino associada a castração, efeminação e seu relacionamento com Domiciano por meio do termo puer. Por exemplo, nos versos a seguir, Marcial usa puer para relacionar Earino a outros dois personagens míticos: Átis e Ganimedes.

\section{[...] apelido que mais quereria o efebo de Cíbele [Átis] e o que faz a mistura nas taças do Tonante [Ganimedes] (Marcial, Epigramas, 9.11.6-7, tradução nossa, grifo nosso). ${ }^{12}$}

As análises abordadas denotam a intenção dos autores de explorar a efeminação do menino Earino, principalmente por meio de termos e expressões que o vinculavam ao papel de esposa ou de amante, bem como sua caracterização com elementos da indumentária e do sexo feminino. Mas as representações não param por aí. Ganimedes e Átis, amantes de seres divinos, entraram em jogo na criação da imagem de Earino. Comecemos por Átis.

\section{AMANTES MUTILADOS: RELAÇÕES ENTRE ÁTIS E EARINO}

A comparação de Earino com Átis e Ganimedes pode informar que a relação entre o garoto e o imperador era afetiva e sexual. Átis era o amante de Cibele, deusa de origem oriental introduzida nos cultos religiosos romanos durante as Guerras Púnicas (264-146 a.C). A história mítica do casal e, principalmente, a imagem de Átis serviram de modelo para Marcial e Estácio caracterizarem seus eunucos, em especial Earino. Deixemos a figura de Ganimedes para ser discutida mais adiante.

As histórias de Átis, namorado da deusa Cibele, e de sua castração são representadas em diversos textos latinos, sendo os mais conhecidos aqueles de Ovídio (Fast., 4.223) e Catulo (Cat., 63). Segundo esses autores latinos, graças ao fato de Átis ser um jovem de extrema beleza, Cibele se apaixona por ele e exige dele um voto de castidade. O rapaz quebra esse voto e trai a deusa com uma ninfa. Cibele, por sua vez, ao saber da traição, assassina a ninfa, o que faz Átis entrar em estado de loucura. Ele acaba cortando o próprio pênis e morrendo por causa do sangue que se esvaiu da ferida aberta com uma faca. A história de Átis conta ainda que, sobre o local onde se concentrou o sangue dele, um jardim de violetas floresceu.

\footnotetext{
${ }^{11}$ No original: "But while such tastes among Romans must have been influenced to some extent by Greek pederastic traditions, they must also be understood in the context of a Roman valorization of youth and young bodies connected with an aesthetic preference for smooth bodies and faces; after all, both puella ("girl") and puer ("boy") could be used to refer to a man's sexual object regardless of his or her age, and also to his slave".

${ }^{12}$ No original: "[...] quo mallet Cibeles puer vocari/ et qui pocula temperat Tonan".
} 
O culto a Cibele foi integrado ao calendário oficial romano. Ela recebeu um templo próprio, e a festa em sua honra e à de Átis foi estabelecida entre os dias 15 e 27 de março. De acordo com Amanda Giacon Parra (2010), no primeiro dia aconteciam as preparações para o início das celebrações. Os seis dias seguintes eram ocupados pelo então chamado castus matris deus, um período de abstinência que requeria restrições alimentares e proibição de práticas sexuais, momento em que todos os participantes representavam ritualmente a dor de Cibele por ter perdido seu companheiro Átis.

No dia 22, a cerimônia intrat arbor era realizada. Nela, os participantes carregavam até o santuário da deusa alguns instrumentos próprios dos rituais: a siringe, um tipo de flauta feita com caule de cana, também conhecida na Antiguidade como flauta de Pã; a verga, uma vara flexível de madeira ou metal; címbalos; tímpanos e flautas duplas amarradas a pequenos galhos. No dia 24, o dies sanguinis, os homens que se consagrariam à deusa eram castrados, tornando-se galli, e,

seguindo o exemplo de Átis, os fiéis se flagelavam ao som dos instrumentos rituais. A alegria voltava a reinar nas festividades somente no dia 25 , quando Átis ritualmente voltava a viver. $\mathrm{O}$ dia 26 era um dia de repouso chamado requietio. E dia 27 havia a cerimônia da lavatio (PARRA, 2010, p. 38).

As comparações feitas por Estácio e Marcial não se encerram em Átis, mas os próprios galli são muitas vezes lembrados quando tratam de Earino. ${ }^{13}$ No que diz respeito às comparações a Átis, no epigrama 9.11 Marcial também traz algumas delas. Isso pode ser visto logo no primeiro verso: "nomen cum violis rosisque natum" ("o nome, com violetas e rosas nascido").

Como escreve Henriksén (1998), na literatura latina as violetas eram consideradas as mensageiras da primavera porque eram as primeiras flores a aparecer em Roma nesse período do ano. Isso, ainda de acordo com Henriksén, pode ser inferido porque em outros textos latinos, como os de Arnóbio e Ovídio, a violeta é uma metáfora para Átis. Como mencionado, no solo em que se depositou o sangue esvaído pela autocastração de Átis nasceu um campo de violetas. Isso pode ser confirmado no sexto verso do mesmo epigrama, quando Marcial faz menção direta a Átis: "quo mallet Cibeles puer vocari" ("apelido que mais quereria o efebo de Cíbele").

A menção às rosas também se dá pelo fato de que, em Roma, tais flores eram as que desabrochavam já no fim da primavera. Há que se mencionar ainda que o epigramatista já denuncia, antes mesmo de citar o nome de Earino (algo feito apenas no décimo terceiro verso), que se tratava de um eunuco. Talvez aqui encontremos uma ironia nos versos de Marcial. Diversos de seus poemas, ao tratar dos galli e de Átis, caracterizam-nos como seres monstruosos, ridículos e dignos de pena. A menção do amante de Cibele neste verso pode não ser simplesmente elogiosa, mas também uma forma de o poeta lembrar o horror que ronda a história de Átis.

\footnotetext{
${ }^{13}$ Para reflexões mais profundas acerca das representações dos galli e de Átis construídas pelo epigramatista Marcial, consultar Ribeiro Junior (2016). Além disso, para ter acesso a um texto que se dedicou especialmente ao tema, conferir Ribeiro Junior (2014).
} 
Estácio também faz conexões entre os dois castrados em seu poema. Para descrever a beleza de Earino, a deusa Vênus o comparou e o considerou superior a quatro outros pueri: Átis, Hilas, Endimião e Narciso.

\author{
Nada tão doce em todo o mundo \\ Que tenha visto ou dado à luz, eu confesso \\ Os meninos do Latmos [Endimião] e do Sangarius [Átis] darão \\ livremente a você \\ e aquele que a vã imagem em uma fonte e um amor estéril \\ consumiram [Narciso] \\ As Naiades azul-celeste teriam preferido você e carregado a \\ sua urna \\ Com um punho mais forte para arrastá-lo para baixo [Hilas] \\ Menino, você está além de todos eles; \\ mais bonito que ele somente a quem você deve ser dado \\ [Domiciano] \\ (As Silvas, 3.5. 39-45, grifo nosso). ${ }^{14}$
}

Sangarius era um rio da antiga Frígia, hoje denominado Sakarya e localizado na atual Turquia. De acordo com Laguna Mariscal (1992), a citação do rio no excerto apresentado é uma metonímia para puer frígio - em outras palavras, Átis. Vout (2007) observa que alguns galli, pela ocasião da aposentadoria de um de seus companheiros sacerdotes e para agradecer aos trabalhos de Cibele, fizeram também uma oferta de mechas de cabelos e as enviaram para o Sangarius, acompanhadas de alguns ornamentos e acessórios usados nos rituais em honra à deusa.

A informação fornecida por Vout corrobora o argumento de Laguna Mariscal de que o trecho do poema em destaque é uma referência ao culto de Cibele e seu namorado. Igualmente, deve-se levar em conta que a manumissão dos escravos obedecia a um ritual parecido: no momento que o mestre libertava um de seus servos, este fazia um corte de cabelo para representar sua liberdade.

Quase no fim do poema, Estácio descreve o envio dos cabelos do eunuco para o templo de Esculápio, o que lembra o episódio mencionado por Caroline Vout:

[...] em seguida, eles [cupidos de Vênus] cortaram as mechas com as setas ligadas

e colocaram-nas sobre ouro e pedras preciosas.

A Mãe Vênus pega à medida que elas caem e unge-as, mais uma vez com suas essências secretas.

Em seguida, falou um menino da multidão

que tinha por acaso que carregar, nas mãos viradas,

o espelho resplandecente ornamentado com ouro:

"Deixe-nos dar isso também. Nenhum presente será mais bem-vindo a esse templo nativo; ele será mais potente que o próprio ouro.

Basta você fixar o olhar nele e deixar o seu para sempre lá."

\footnotetext{
${ }^{14}$ No original: "nil ego, nil, fateor, toto tam dulce orbe/aut vidi aut genui. cede tibi Latmanius ultro/ Sangariusque puer, quemque irrita fontis imago/Et sterilis consumpsit amor. te caerula Nais/mallet et apprensa traxisset fortius urna./tu, puer, ante omnes; solus formosior ille/cui daberis".
} 
Assim falou e fechou o espelho, capturando a imagem (Estácio, As Silvas, 3.4. 90-98). ${ }^{15}$

O tema do corte e da oferta de cabelos está presente nos dois poetas. Marcial escreveu dois epigramas sobre o assunto, nos quais menciona, do mesmo modo, a oferta das mechas acompanhadas de ornamentos. O primeiro está reproduzido a seguir:

Um espelho, conselheiro da beleza, e doces cabelos, como sacros, ao deus de Pérgamo ofereceu o menino que ao seu senhor é grato mais que a corte inteira, e que assinala com seu nome o tempo primaveril. Afortunada a terra honrada de tal presente! Nem de Ganimedes preferia ter a cabeleira (Epigramas, 9.16). ${ }^{16}$

O poema subsequente continua relatando o mesmo episódio:

Venerando neto de Latona, que com ervas gentis refreias a trama e os velozes fusos das Parcas, estes cabelos, do senhor louvados, para ti ex-voto raro, da Urbe do Lácio tos envia aquele teu jovem patrício; e, com os divinos cabelos, um disco espelhante, que foi juiz constante da ventura do seu rosto. Guarda-Ihe a juvenil graça, para mais belo não ser de longos cabelos que de cabeleira aparada (Marcial, Epigramas, 9.17). ${ }^{17}$

Os excertos de Estácio e Marcial, se comparados às observações de Vout já mencionadas, podem reforçar a ideia de que o garoto tinha desejos de deixar os serviços de seu mestre. No caso, esse mestre seria Domiciano. Se aliarmos também isso aos apontamentos de Wiliams (2010), que afirmam que, quando os pueri deixavam de servir sexual e afetivamente aos seus senhores, tinha lugar o primeiro aparo de suas barbas e seus cabelos, o argumento ganha ainda mais força. Entretanto, tal ideia pode ser abalada, uma vez que nem Estácio nem Marcial mencionam como e quando se deu a manumissão de Earino ao longo de seus textos.

\footnotetext{
${ }^{15}$ No original: "[...] tunc iunctis crinem incidere sagittis/atque auro gemmisque locant; rapit ipsa cadentem/ mater et arcanos iterat Cytherea liquores./tunc puer e turba, manibus qui forte supinis/nobile gemmato speculum portaverat auro,/'hoc quoque demus' ait 'patriis nec gratius ullum/munus erit templis, ipsoque potentius auro,/tu modo fige aciem et vultus hic usque relinque.' sic ait et speculum seclusit imagine rapta". ${ }^{16}$ No original: "Consilium formae speculum dulcisque capillos/Pergameo possuit dona sacrata deo/ille puer tota domino gratissmus aula,/nomine qui signat tempora verna suo./felix quae tali censetur munere tellus!/nec Ganymedes mallet habere comas".

${ }^{17}$ No original: "Latonae venerande nepos, qui mitibus herbis/Parcarum exoras pensa brevesque colos,/ hos tibi laudatos domino, rata vota, capillos/ille tuus Latia misit ab urbe puer;/addidit et nitidum sacratis crinibus orbem,/quo Felix fácies iudice tuta fuit./tu iuvenale decus serva, ne pulchrior ille/in longa fuerit quam breviore coma".
} 
Se Estácio escreveu o prefácio do terceiro livro das Silvas quando Earino já não era mais escravo de Domiciano, ${ }^{18}$ não menciona que isso aconteceu na ocasião do corte dos cabelos de Earino. De uma forma ou de outra, transparece aí uma possibilidade de o garoto estar infeliz com sua condição. Ou, o que é mais provável, Estácio e Marcial enaltecem esse evento da história do puer de Domiciano ao mesmo tempo que relatam, implicitamente, sua reprovação às práticas sexuais e afetivas do imperador.

A menção ao templo de Esculápio em Pérgamo, local para onde foi enviado o cabelo de Earino, também pode ser uma referência à história do casal divino da Frígia, já que, na Antiguidade, Pérgamo era um grande centro do culto de Cibele e Átis (VOUT, 2007).

Assim, pode-se provavelmente inferir que a relação entre Earino, Átis e a aposentadoria de um gallus enfoca também noções sobre o relacionamento do menino com o imperador, o vínculo afetivo-sexual entre estes e a recusa do garoto em continuar nessa união. Para compreender a complexa relação entre puer e dominus, cabe colocar outro amante em cena: Ganimedes.

\section{ENTRE OS CÉUS E A TERRA: A IDEOLOGIA IMPERIAL E AS REPRESENTAÇÕES DE EARINO COMO GANIMEDES}

Ganimedes sempre foi um personagem comum nos epigramas de Marcial para descrever garotos escravos que serviam aos interesses sexuais de seus donos. Isso pode ser visto quando se atenta para os epigramas $2.43 ; 3.39 ; 5.55 ; 10.98$ e 11.104 . Estácio também usou a figura do puer de Júpiter em suas obras, como a Aquileida, mas As Silvas 3.4 são um caso especial.

O que se deve mencionar é que as comparações feitas entre esses dois pueri por Estácio e Marcial não se deram ao acaso ou para conferir mais matizes às suas construções de papéis de gênero, mas obedecem à ideologia imperial estabelecida por Domiciano. Segundo Carole Newlands (2002), tal ideologia se valeu dos poetas que viviam à custa dos seus patronos para construir uma imagem enaltecedora de Domiciano e suas políticas em relação a Roma e ao império.

Em todos os cincos livros d'As Silvas, mesmo quando Estácio não se refere ao imperador, veem-se presentes construções literárias para criar uma figura do princeps como bom governante, marido e homem público. Marcial também usa seus epigramas para elaborar representações positivas acerca de Domiciano e sua corte. Dessa maneira, elementos mitológicos e, acima de tudo, a corte imperial são evocados constantemente sob o pretexto de propagandear o governo de Domiciano.

Além disso, mas de forma alguma menos importante, questões referentes às sexualidades e aos papéis de gênero são utilizadas e combinadas com temas religiosos para criar uma representação positiva de alguns eventos que poderiam desqualificar a imagem imperial de Domiciano e, consequentemente, sua autoridade e seu poder. É nessa última observação que se ligam Earino e Ganimedes. A castração de Earino ocupa um lugar paradoxalmente importante no contexto da construção da ideologia imperial de Domiciano.

\footnotetext{
18 "Earino praeterea, Germani nostri libertus"; "Earino, liberto de nosso Domiciano” (Estácio, As Silvas 3.4.17).
} 
Por um lado, como já se tem problematizado neste texto, o corpo emasculado de Earino é um empecilho para os autores antigos conseguirem criar e manter uma imagem séria e coerente da corte imperial e das normas regulatórias de gênero esperadas dos romanos e, especialmente, do casal imperial: Domiciano e Domícia. Por outro, Earino se torna uma ferramenta fundamental e um personagem central para aumentar e legitimar o poder de Domiciano. Earino e seu corpo-problema saem de uma zona de abjeção tanto das hierarquias políticas romanas quanto das hierarquias dos gêneros para ocupar um lugar entre os deuses - Marcial e Estácio construíram paralelos entre Earino e Ganimedes.

Nessa comparação, todavia, Estácio e Marcial produzem uma imagem do eunuco que obedece à ideologia de divinização de Domiciano. Em tal ideologia, Domiciano é representado como Júpiter, e a imperatriz Domícia, como Juno. Earino é colocado como o copeiro do casal imperial, o que o eleva ao nível divino de Ganimedes. Newlands (2002) defende que representar Earino como Ganimedes era tão importante quanto associar Domiciano a Júpiter, uma questão central para a divinização do imperador ainda vivo.

David Vessey (1973) explica que a aproximação entre Earino e Ganimedes é extremamente significativa para dar ao casal imperial uma imagem de divindades. Além de tudo, era crucial criar uma aura harmônica entre o trio, para esconder ou pelo menos amenizar a aberração que poderia parecer o triângulo (amoroso?) composto por Earino, Domiciano e Domícia.

Estácio representa o casamento de Domiciano e Domícia com harmonia, diferentemente do mito no qual a deusa Juno, muito ofendida com o relacionamento entre Ganimedes e seu esposo Júpiter, se torna ciumenta e agressiva. O excerto a seguir, extraído dos versos das Silvas, mostra a intenção de Estácio em representar Domícia não só como a versão terrena de Juno, mas como superior à deusa, uma vez que aprovaria o romance entre o imperador e o eunuco.

Pérgamo, de longe mais afortunado que as folhas dos pinheiros de Ida,

Embora Ida se orgulhe sobre as nuvens de um abuso divino (Com certeza ele deu o menino [Ganimedes] aos deuses superiores

A quem Juno sempre olha com desconfiança, recuando sua mão e recusando o néctar)

Mas você tem o auxílio dos deuses, especialmente elogiado por seu justo curandeiro.

Você enviou ao Lácio um servo cujo Júpiter ausônio

[Domiciano]

e a Juno romana [Domícia] respeitam gentilmente, ambos

aprovando;

E, com a aprovação dos deuses,

o senhor da terra [Domiciano] está tão satisfeito

(As Silvas, 3.4.12-20). ${ }^{19}$

\footnotetext{
${ }^{19}$ No original: "Pergame, pinifera multum felicior Ida,/illa licet sacrae placeat sibi nube rapinae/(nempe dedit superis illum quem turbida semper/luno uidet refugitque manum nectarque recusat),/at tu grata deis pulchroque insignis alumno/misisti Latio placida quem fronte ministrum/luppiter Ausonius pariter Romanaque luno/aspiciunt et uterque probant. nec tanta potenti/terrarum domino diuum sine mente uoluptas".
} 
Nesse excerto, nota-se que, quando levado de Pérgamo para Roma, Earino é aceito tanto por Domiciano quanto por Domícia. Sabe-se que, na história divina, Juno reprova veementemente o relacionamento de Júpiter com Ganimedes. Na história de Estácio, Domícia é representada como superior à própria deusa, uma vez que não desaprova o relacionamento entre Earino e Domiciano. Isso também fundamenta a representação da imperatriz como a esposa que respeita as decisões de seu marido e age com gentileza para preservar a harmonia do casal, reforçando papéis e performances de gênero idealizados pela elite romana.

Estácio menciona no verso 15 que Juno sempre olhou com desconfiança para o puer e que ela recusava seu néctar. Nesse verso, o autor está se referindo à função de copeiro desempenhada por Ganimedes, que o incumbia de servir a mesa do casal divino com vinho. Porém, a palavra usada por Estácio é nectar, com traduções para o português como néctar ou mel. Gabriel Laguna Mariscal (1992) esclarece que o uso da palavra nectar denuncia, quando se trata da literatura latina desse período, um contexto erótico da cena representada. Assim, pode-se entender que Juno, além de estar enraivecida com a presença do menino, também se recusa a compartilhar das experiências erótico-afetivas entre o deus e Ganimedes.

Se o imperador corresponde a Júpiter n'As Silvas e na formulação e propagação de sua ideologia imperial, precisa ter um copeiro, assim como seu correspondente celeste: "O relacionamento entre Earino e Domiciano é sugestivamente sexualizado; Earino é descrito por Vênus como 'um escravo para o amor palatino' (Palatine famulus amori; 38)" (NEWLANDS, 2002, p. 107, tradução nossa). ${ }^{20}$ Desse modo, o relacionamento sexual entre o imperador e o eunuco, segundo Carole Newlands, é o ponto central de todas as tensões no poema: Ocidente e Oriente, passado e presente, moral tradicional e contemporânea, masculino e feminino, poder e, ao mesmo tempo, submissão de Earino.

Os demais relatos latinos, no entanto, não retratam o comportamento de Domícia como esposa solícita ou passiva em seu casamento com Domiciano, como foram os casos de Suetônio e Dion Cassio. Marcial, no seu último epigrama dedicado ao eunuco, é um dos autores que representam a imperatriz de modo diferente ao de Estácio, especialmente em relação a Earino:

Ao ver o escanção ausónio de cabelo cortado ao todo [Earino], disse o jovem frígio, no enlevo do outro Jove [Jupiter]: "Estás a ver o que o teu César permitiu ao favorito; permite-o também ao teu, ó supremo senhor. Já a longa cabeleira me oculta a penugem primeira, já de mim troça a tua Juno e másculo me chama." "Ó rapazinho dulcíssimo", Ihe respondeu o pai celeste, "não sou eu, é a situação a recusar o que pedes: escanções iguais a ti tem o nosso César mil e o grande palácio mal abarca os jovens celestiais, mas se o corte do cabelo te der um rosto viril,

\footnotetext{
${ }^{20}$ No original: "[...] the relationship between Earinus and Domitian is suggestively represented as a
} sexual one; Earinus is described by Venus as 'a slave to Palatine love'" (Palatine famulus amori, 38). 
que o outro me restará para misturar o néctar?"

(Marcial, Epigramas, 9.36)..$^{21}$

Aqui, Marcial representa o ciúme de Juno como uma metáfora e a razão para o corte dos cabelos de Earino. Garthwaite (1994) sugere que, no epigrama reproduzido, Domícia ridiculariza Earino porque ele mascara, com seus longos cabelos, sua masculinidade e a entrada na adolescência, representada pelo aparecimento da barba. A barba poderia indicar que o menino estava se tornando um homem, e assim as relações homoeróticas com seu senhor deveriam ter um fim. Garthwaite defende que aqui há um ponto muito diferente no namoro entre Earino e Domiciano, uma vez que Júpiter não emascula Ganimedes para continuar seu relacionamento sexual com o garoto.

No caso de Estácio, ele não expõe diretamente a diferença entre as duas histórias. Como anota Caroline Vout (2007), Estácio faz uso de uma ferramenta muito mais ardilosa, provavelmente temendo o perigo da exposição de suas (talvez) reais concepções sobre o relacionamento entre o menino e o imperador. Ele coloca lado a lado as duas versões, a de Juno enraivecida e a de Domícia calma e passiva. Mesmo que não tenha feito como Marcial, Estácio deixa claro aos seus leitores a diferença entre tais relacionamentos, ficando para os receptores de seu poema a função de pensar quão estranho era o relacionamento de Domiciano e Earino, bem como, consequentemente, a reação de Domícia (VOUT, 2007).

\title{
"CORPOS CASTRADOS": O IMPERADOR, O ESCRAVO E OS AUTORES
}

Sobre o processo de castração de Earino, é Estácio quem oferece a única informação que se tem:

\author{
Uma vez o deus da sua terra também deixou a grandiosa \\ Pérgamo para atravessar o mar para que a primeira barba não \\ desfigurasse suas bochechas brilhantes \\ e escurecesse as alegrias de sua beleza. \\ A ninguém menos foi confiado o poder de suavizar o rapaz, \\ do que à habilidade silenciosa filho de Febo [Esculápio] \\ que gentilmente pediu a este corpo para deixar o seu sexo, \\ não sendo ferido com qualquer corte \\ No entanto, Vênus está atormentada pela preocupação, temendo \\ que o garoto pudesse sofrer. \\ Ainda não havia começado a clemência do nosso nobre líder \\ para manter os meninos intactos desde o nascimento. \\ Agora é proibido suavizar o sexo e mudar a masculinidade; \\ a natureza se regozija em ver apenas aqueles que ela criou. \\ Nunca mais uma lei perversa fará as mães de escravos
}

\footnotetext{
${ }^{21}$ No original: "Viderat Ausonium posito crine ministrum/Phryx puer, alterius gaudia nota lovis:/'quod tuus ecce suo Caesar permisit ephebo,/tu permitte tuo, maxime rector' ait;/'iammihi prima latet longis lanugo capillis,/iam tua me ridet luno vocatque virum.'/cui pater aetherius 'puer o dulcissime', dixit,/'non ego quod poscis, res negat ipsa tibi:/Caesar habet noster similis tibi mille ministros/tantaque sidereos vix capit aula mares;/at tibi si dederit vultus coma tonsa viriles,/quis mihi qui néctar misceat alter erit ?"'.
} 
temerem suportar o fardo dos filhos.

(Estácio, As Silvas, 3.4.65-77). ${ }^{22}$

Para Henriksén (1997), o verso 70, "leniter haud ullo concussum vulnere corpus", "não sendo ferido com qualquer corte", indica que a castração de Earino teria ocorrido pelo método de esmagamento, e não de excisão. ${ }^{23}$ Se a afirmação de Henriksén estiver correta, tal forma de narrar a castração pode ter sido escolhida por Estácio para fazer com que o episódio parecesse menos agressivo aos olhos dos leitores.

Não muito afeitos à prática da emasculação, os romanos se horrorizavam com o relato de Catulo sobre a castração de Átis - violenta, sangrenta e que o levou à morte. Carole Newlands (2002) explica que esse não é o único ponto instigante da narrativa do excerto que merece atenção. Esculápio, cultuado no Oriente como deus da medicina, sendo seu culto conhecido em Roma e seguido por diversos sujeitos, sobretudo nos grupos menos elitistas, é o responsável pela supressão dos testículos de Earino. O poeta invoca as habilidades cirúrgicas do deus da medicina para criar a impressão de que o processo foi realizado com cuidado e perícia, sem causar maiores danos ao corpo do menino.

Assim, a castração de Earino foi, em primeiro plano, gentilmente executada, sem nenhum aspecto estranho ou monstruoso. Da mesma forma, Estácio faz questão de se referir a uma divindade de origem estrangeira, afastando esse tipo de procedimento do cotidiano e das práticas religiosas romanas. ${ }^{24}$

Além disso, Laguna Mariscal (1992) pontua que a palavra olim, que inicia o trecho do poema que tratará justamente da castração, é uma marca lexical que introduz uma fábula, uma história fantasiosa e imaginária. Tal palavra é correspondente à expressão que inicia a maioria dos contos de fadas modernos: era uma vez. Isso coloca o relato da emasculação de Earino longe do universo real, distanciando mais uma vez o episódio do cotidiano romano.

Outro fator que se deve considerar na análise desse fragmento do poema 3.4 é o problema de lidar com um assunto delicado como a castração, uma vez que os poemas de Estácio e Marcial tinham a obrigação de bajular o eunuco de seu patrono, Domiciano. Isso se dá por dois motivos. Primeiro, o tema já era espinhoso em si, pois as representações dos eunucos na literatura latina, como se tem visto aqui, são todas

\footnotetext{
${ }^{22}$ No original: "olim etiam, ne prima genas lanugo nitentes/carperet et pulchrae fuscaret gaudia formae,/ ipse deus patriae celsam trans equora liquit/Pergamon. haud ulli puerum mollire potestas/credita, sed tácita iuvenis Phoebeius arte/leniter haud ullo concussum vulnere corpus/de sexu transite iubet. tamen anxia curis/mordetur puerique timet Cytherea dolores./nondum pulchra ducis clementia coeperat ortu/ intactos servare mares; nunc frangere sexum/atque hominen mutare nefas, gavisaque solos/quos genuit Natura videt, nec lege sinistra/ferre timent famulae natorum pondera matres".

${ }^{23}$ Shackleton Bailey, numa nota de rodapé de sua tradução d'As Silvas (STATIUS, 2003), escreve que esses versos provam que Earino não teria sido castrado. É difícil confirmar esse raciocínio, uma vez que Bailey não oferece outro dado. Tanto na literatura especializada quanto na documentação antiga consultada para escrever este artigo não se encontrou nenhum outro autor, clássico ou moderno, que endossasse esse argumento.

${ }^{24}$ A relação entre o imperador Nero e outro eunuco, Esporo, nos faz lembrar essa passagem de Estácio. Suetônio narra o relacionamento e o casamento de Nero e Esporo como um acontecimento estranho às normas romanas de gênero, buscando vinculá-lo às práticas pederásticas gregas. Parece, assim, que a "estrangeirização" de práticas sexuais e de gênero indesejadas pode ser uma tentativa de afastá-las da cultura romana. Ver, em RIBEIRO JUNIOR, 2016, uma reflexão aprofundada sobre a relação entre Nero e Esporo.
} 
jocosas e desqualificam a experiência deles. Segundo, Marcial e Estácio tinham que lidar com o fato de que precisavam bajular o puer delicatus castrado de Domiciano, que havia proibido a castração mais ou menos uma década antes da escrita dos textos. As incoerências e as tensões de gênero nos textos acompanham as tensões políticas que perpassam o governo de Domiciano.

No fim do trecho que narra a castração, Estácio faz questão de deixar explícita a lei de Domiciano contra a emasculação (versos 73 a 77), como maneira de provar que Earino era um caso excepcional e que o imperador não tinha nenhuma ligação com o que aconteceu com o garoto. Além disso, frisa que, a partir da criação da lei, nenhum outro menino teria que deixar sua masculinidade ou suavizar seu sexo e que a castração só foi possível porque acontecera antes da clemência de Domiciano reconhecer tal prática como crime.

De acordo com Henriksén (1997), se Earino foi castrado pelo método de esmagamento, isso deve ter acontecido por volta dos dois ou três anos de idade. Para que o princeps não desobedecesse à própria lei, antes de 82-83 d.C. Todavia, Ombretto Pederzani (1992) explica que, mesmo depois da proibição, os eunucos ainda eram comuns em Roma e as castrações não deixaram de existir, sendo difundidas em todo o território do império. O que pode confundir qualquer interpretação é que Estácio narra a castração do menino logo após a chegada dele ao palácio de Domiciano no Palatino. De qualquer maneira, Estácio coloca a castração de Earino num contexto mítico: a emasculação só foi realizada graças ao desejo de Vênus e pelas mãos de Esculápio.

Sobre a influência de Vênus nesse processo, a deusa do amor é colocada, alguns versos antes do relato da emasculação, como a responsável por ele, visto que a divindade ficou maravilhada com a beleza pueril de Earino e, para mantê-la intacta, o entregou aos cuidados de Esculápio. Os versos 21-25 encontrados n'As Silvas 3.4 relatam a chegada de Vênus ao templo de Esculápio em Pérgamo, onde a divindade depara com o garoto e se dá o seguinte:

Ela vê um menino, brilhando com a estrela beleza inigualável, brincando diante do altar do próprio deus.

Enganada à primeira vista por um breve momento, ela crê que ele é um dos seus filhos;

mas ele não tinha nenhum arco e nem tons radiantes saltando de seus ombros.

Ela pergunta a sua graça juvenil, olhando para seu rosto e cabelo e diz "Irás para as torres ausônias negligenciado por Vênus?

Terás uma habitação desprezível e um jugo de comum servidão? Longe! Eu devo dar esta beleza ao senhor que a merece.

Venha agora comigo, menino, venha!

Eu voarei com você através das estrelas

na minha carruagem alada até o líder, um presente de dádivas.

Nenhuma servidão comum espera por você

você está destinado a servir com dignidade no Palatino"

(As Silvas, 3.4.26-38). ${ }^{25}$

\footnotetext{
${ }^{25}$ No original: "hic puerum egregiae praeclarum sidere formae/ipsius ante dei ludentem conspicit aras./ ac primum subita paulum decepta figura/natorum de plebe putat; sed non erat illi/arcus et ex umeris
} 
Como se vê, o relacionamento de Domiciano e Earino começa pelas bênçãos de Vênus, deusa que escolhe o garoto para servir ao imperador. Em outras palavras, como Perderzani (1992) mostra, Estácio não representa o imperador como agente da castração, mas que apenas recebeu o puer com sua divina compreensão, dentro de sua própria casa, dedicando a ele seu amor e sua família.

Essa questão poderia ser agravada pela lei existente contra a castração de meninos e escravos, promulgada pelo próprio Domiciano. Tal lei é, provavelmente, do ano 82 ou 83 d.C. e vem acompanhada da reedição de outra antiga lei que também fixa rígidos papéis de gênero: a Lex Scatinia, que foi

criada em 227 a.C. com o objetivo de punir com a morte todo aquele que submetesse um cidadão ao estupro violento. No final da República e início do Principado, a lei era aplicada apenas nos casos de tentativas e/ou estupros de rapazes livres (stupro cum pueri), incidindo sobre o adulto responsável pelo estupro e sobre o cidadão romano que assume o papel passivo. Em ambos, a penalidade era o pagamento de dez mil sestércios, o que leva Cantarella a afirmar que a Lex Scatinia "no era absolutamente respetada" (FEITOSA, 2014, p. 68).

Na reedição de Domiciano, tornou-se mais severa a punição também para matronas que cometessem adultério. Assim, o principado de Domiciano se caracteriza pela tentativa de regular condutas corporais e de gênero por meio de atos legislativos. Porém, tais medidas, não só as de Domiciano, não tiveram um efeito prático:

A castração tinha sido há muito tempo uma marca física de escravidão (de escravos trazidos de fora do império) e de devoção religiosa nos então chamados cultos orientais. Embora Domiciano e Nerva tivessem banido a castração dentro das fronteiras do império e Adriano tivesse feito dela um crime capital para o castrador e o castrado, as leis evidentemente não se aplicavam àqueles que castravam a si mesmos, e a prática continuou, como tinha sido por centenas de anos, entre os galli, sacerdotes e devotos de Cibele (Magna Mater), Atargatis e a deusa cítica (CANER, 1997, p. 398-399, tradução nossa). ${ }^{26}$

Como se mencionou no início desta seção, a proibição da emasculação é citada tanto por Dion Cássio (História de Roma, 67.2.3) quanto por Suetônio (Dom, 7). Nas obras de Marcial e de Estácio, essa lei domiciana é trazida à tona em

nullae fulgentibus umbrae./miratur puerile decus, uultumque comasque/aspiciens 'tune Ausonias' ait 'ibis ad arces/neglectus Veneri? Tu sordida tecta iugumque/seruitti uulgare feres? Procul absit: ego isti/quem meruit formae dominum dabo. uade age mecum,/uade, puer: ducam uolucri per sidera curru/ donum immane duci; nec te plebeia manebunt/iura: Palatino famulus deberis armori".

${ }^{26}$ No original: "Castration had long been the physical mark of slavery (of slaves brought in from outside the empire) and of religious devotion in the so-called oriental cults. Although Domitian and Nerva had banned castration within the borders of the empire and Hadrian had made it a capital offense for both castrator and castrated, the laws evidently did not apply to those who had castrated themselves, and the practice continued, as it had for hundreds of years, among the "Galli" priests and devotees of Cybele (Magna Mater), Atargatis and the Scythian goddess". 
lugares estratégicos. Para Sullivan (1991), o fato de Marcial não a mencionar até as proximidades do ano de 94, provavelmente o mesmo ano em que Earino envia seus cabelos a Pérgamo, pode indicar certa crítica ao imperador e seu relacionamento com um eunuco, à contradição de suas medidas e ao fato de transgredir normas sociais e regulatórias de gênero vigentes à época.

Há ainda outro interessante argumento defendido por Garthwaite (1994). No epigrama 9.2, não por acaso, Marcial introduz o assunto da castração. É narrada a prece de Lupo - um patrono que não dispensa a devida atenção aos seus dependentes e aos seus clientes - a Cibele para não castrar seus jovens acólitos. Marcial encerra o epigrama dizendo que é o próprio Lupo que merece ser castrado. Garthwaite se pergunta se esse fim é uma metáfora para Domiciano que desconsidera seus clientes - que poderiam ser poetas próximos à corte, como Marcial e Estácio -, suas próprias leis, e emascula um jovem menino com a intenção de mantê-lo como puer delicatus.

No fim d'As Silvas 3.4, pode-se ver um caso parecido. Quando Earino envia seus cabelos ao templo em Pérgamo, o menino faz uma prece a Esculápio para preservar a eterna juventude de Domiciano.
Mas o incomparável garoto, estendendo suas mãos às estrelas "Em troca desses presentes, doce protetor da humanidade, Que você queira, se eu tenho tanto para merecer, Renovar a juventude do nosso senhor e preservá-lo para o mundo.
As estrelas pedem isso junto a mim, e as águas as terras também.
Deixe-o, eu peço, passar pelos anos Ilian e Pylian, regozijando-se de sua própria casa e o templo Tarpeian envelhecerem junto com ele."
Assim falou, e Pergamo imaginou que os altares tremeram (As Silvas, 3.4.99-106). ${ }^{27}$

Tal trecho remete a outro do poema. Antes de narrar a emasculação de Earino, Estácio relata que o menino teria sido castrado para preservar a beleza e os traços jovens:
Garoto querido dos supremos, escolhido para saborear primeiro o néctar venerado e tocar tantas vezes aquela poderosa mão,
a mão do Getae procura conhecer persas e armênios, os índios para tocar
Oh, nascido sob uma estrela da sorte, os deuses têm preferido você Uma vez também o próprio deus de sua terra
Deixou a grandiosa Pérgamo para atravessar o mar para que a primeira barba não estrague suas bochechas

\footnotetext{
${ }^{27}$ No original: "At puer egrerius tendens ad sidera palmas,/'his mihi pro donis, hominum renovare iuventa/atque orbi servare velis. hoc sidera mecum/hoc undae terraeque rogant eat, oro, per anos/ lliacos Pyliosque simul, propriosque penates/Gaudeat et secum Tarpeia senescere templa'/Sic ait, et motas miratur Pergamos aras".
} 
brilhantes e escureça alegrias da sua beleza

(As Silvas, 3.4.60-67)..$^{28}$

Laguna Mariscal (1992) afirma que Estácio, por meio da prece de Earino, sugere que Domiciano também merecia ser castrado, como uma espécie de crítica às ações do imperador, e que o poeta poderia ter sido forçado a retornar a Nápoles por ordens de Domiciano. N'As Silvas 3.5, o poema seguinte ao de Earino, escrito em forma de carta para convencer sua esposa a morar com ele em Nápoles, Estácio não confirma tal evento, mas também não deixa claros os motivos que o fizeram sair de Roma.

Tais representações de Earino nos textos de Marcial e Estácio tornam evidente que escrever sobre o menino castrado que era amante do imperador era um grande desafio. Como se pode ver, as imagens de Earino são contraditórias, haja vista que os poemas enaltecem alguns aspectos de sua história e de seu relacionamento com Domiciano, mas também elaboram críticas irônicas em relação a esses acontecimentos.

Essa variação nas representações, ora bajulando, ora criticando, pode ser entendida como uma prática já muito mais antiga que os textos de Estácio e Marcial: a crítica segura. Para Frederick Ahl, o safe criticism era usado pelos gregos desde o século $V$ a.C., e, em Roma, principalmente no período aqui trabalhado, a crítica segura nada mais era do que a propriedade dos autores "se expressarem com relativa segurança" diante de seus patronos e financiadores (1984, p. 207, tradução nossa).

Deve-se levar em conta que Domiciano tratou seus opositores - poetas, filósofos ou oradores - com mãos firmes. O exílio e a perseguição eram práticas comuns no principado domiciano. Caroline Vout (2007) defende que essa combinação entre a extrema bajulação e as críticas implícitas era uma característica intrínseca do gênero panegírico, especialmente nos autores satíricos e nos poemas de ocasião. A autora afirma que não se trata de simpatizar ou não com o objeto representado ou com quem encomendou o texto, e sim de uma questão estilística muito em voga nesse momento, pois a escrita de Marcial e Estácio "sugere que a poesia deles não é sobre a autenticidade do sentimento. É uma performance virtuosa em excelência literária" (2007, p. 201, tradução nossa). ${ }^{29}$

Assim, as representações aqui analisadas podem sugerir o incômodo em ter que tratar de um tema difícil - a emasculação - quando se é financiado pelo próprio imperador, que, apesar de suas proibições às práticas de castração, mantém relacionamento íntimo com um eunuco. Vout (2007, p. 169, tradução nossa) nos aponta tal problemática:

Isso levanta a questão do que pode significar desejar um corpo castrado e um eunuco exibir desejo. Isso, por sua vez, torna possível uma reavaliação das maneiras pelas quais o corpo do eunuco ou um corpo masculino mutilado, que exibem permanentemente sua falta de potência masculina, ou sua

\footnotetext{
${ }^{28}$ No original: "Care puer superis, qui praelibare verendum/nectar et ingentem totiens contingere dextram/electus, quam nosse Getae, quam tangere Persae/Armeniique Indique petunt! o sidere dextro/ edite, multa tibi divum indulgentia favit./olim etiam, ne prima genas lanugo ninentes/carperet et pulchrae fuscaret gaudia formae,/ipse deus patriae celsam trans aequora liquit".

${ }^{29}$ No original: "[...] suggests that their poetry is not about authenticity of feeling. It is a virtuoso performance in literary excellence".
} 
masculinidade comprometida, podem funcionar como uma metáfora para a própria situação dos poetas em ter que prostituir seus princípios e escrever para agradar seus patronos. ${ }^{30}$

\section{CONSIDERAÇÕES FINAIS OU A SÍLABA REBELDE}

sed tu, syllaba contumax, rebellas. mas tu, teimosa sílaba, rebelde te mostras

(Marcial, Epigramas, 9.11,12).

Entende-se, com base nas análises exploradas, que as representações de Earino fabricadas por Marcial e Estácio expressam a identidade de gênero do eunuco sempre em mudança. Num momento, é divinizada e assexuada, comparada à figura celestial de Ganimedes; noutro, é desqualificada e sexualizada, pela sua castração e sua relação com Domiciano. A identidade do puer não é fixa, mas constantemente reelaborada nos discursos que narram e enaltecem os eventos da corte imperial.

Dessa maneira, a imagem de Earino, como vista em Marcial e Estácio, pode ser pensada como uma crítica às próprias condições nas quais os autores se encontravam, já que sua sobrevivência dependia do trabalho como escritores e clientes do imperador. As tensões políticas apresentadas pelo relacionamento de Domiciano e Earino também acompanham aquelas de gênero. Elas se imbricam num "casamento" que ao mesmo tempo reforça e coloca em tensão tais questões.

Por fim, é necessário esclarecer que um dos problemas encontrados nessa documentação foi justamente não tentar reificar as identidades masculinas e femininas já tão citadas e reiteradas por Estácio, Marcial e todos os outros autores latinos. $O$ maior intento foi visibilizar as experiências/representações do eunuco Earino, não numa tentativa de pensar um terceiro gênero ou uma identidade para os eunucos, pois isso nada mais seria do que uma terceira essencialização. O potencial queer de Earino reside exatamente em ser dissidência, ser uma descontinuidade em relação aos modelos de homem e mulher.

O corpo eunuco, esse corpo sem lugar e estranho, se torna fonte de assombro para os poetas, para as performances e papéis de gênero e para a política imperial. A malha discursiva aqui analisada mostra como esse corpo incômodo foi manejado para reificar as posturas políticas e os papéis de gênero. Como escreveu Marcial sobre o nome de Earino, acredita-se que os eunucos fossem justamente a sílaba rebelde que teimava em desobedecer às narrativas normalizadoras na Antiguidade, sejam literárias, sejam de caráter sexual e de gênero.

\footnotetext{
${ }^{30}$ No original: "It raises the question of what it might mean to desire a castrated body and for a eunuch to exhibit desire. This in turn makes possible a reassessment of the ways in which the body of the eunuch or wounded male body, which permanently display its lack of masculine potency or compromised manhood, can function as a metaphor for the poet's own situation in having potentially to prostitute his principles and write to please his patron".
} 


\section{REFERÊNCIAS}

AHL, Frederick. The Art of Safe Criticism in Greece and Rome. American Journal of Philology, Baltimore, v. 105, p. 174-208, 1984.

BUTLER, Judith. Corpos que pesam: sobre os limites discursivos do "sexo". In: LOURO, Guacira Lopes (org.). O corpo educado: pedagogias da sexualidade. Tradução de Tomaz Tadeu da Silva. 2. ed. Belo Horizonte: Autêntica, 2001. p. 151172.

BUTLER, Judith. Problemas de gênero: feminismo e subversão da identidade. Tradução de Renato Aguiar. Rio de Janeiro: Civilização Brasileira, 2003.

BUTLER, Judith. Regulações de gênero. Cadernos Pagu, Campinas, n. 42, p. 249$274,2014$.

CANER, Daniel F. The Practice and Prohibition of Self-Castration in Early Christianity Vigiliae Christianae, Leiden, v. 51, n. 4, p. 398-399, 1997.

CATULLE. Poiesis. Tradução de Georges Lafaye. Paris: Les Belles Lettres, 1923.

CITRONI, Mário et al. Literatura de Roma Antiga. Tradução de Margarida Miranda, Isaías Hipólito e Walter de Souza Medeiros. Lisboa: Fundação Calouste Gulbenkian, 2006.

DIO CASSIUS. Roman History. v. LXIII. Tradução para o inglês de Earnest Cary, com base na versão de Herbert Baldwin Foster. (Loeb Classical Library.) Cambridge; Massachusetts; London: Harvard University Press, 1993.

FEITOSA, Lourdes Conde. O amor entre iguais: o universo masculino na sociedade romana. In: ESTEVES, Anderson Martins; AZEVEDO, Kátia Teonia; FROHWEIN, Fábio (org.). Homoerotismo na Antiguidade Clássica. Rio de Janeiro: Programa de Pós-graduação em Letras Clássicas da UFRJ, 2014. p. 141-167.

FOUCAULT, Michel. História da sexualidade l: a vontade de saber. Tradução de Maria Thereza da Costa Albuquerque e J. A. Guilhon Albuquerque. 7. ed. Rio de Janeiro: Edições Graal, 1988.

GARTHWAITE, John. The Panegyrics of Domitian in Martial Book 9. Ramus, Cambridge, v. 22, n. 1, p. 78-102, 1994.

GUARINELLO, Norberto Luiz. História Antiga. São Paulo: Contexto, 2013.

HENRIKSÉN, Christer. Earinus: An Imperial Eunuch in the Light of the Poems of Martial and Statius. Mnemosyne, Leiden, Fourth Series, v. 50, n. 3, p. 281-294, 1997.

HENRIKSÉN, Christer. Martial, Book IX: A Commentary. Uppsala: Acta Universitatis Upsaliensis, 1998. 
LAGUNA MARISCAL, Gabriel. Estacio, Silvas III. Introdução, edição crítica, tradução e comentário. Madri: Fundación Pastor de los Estudios Clásicos, 1992.

MARCIAL. Epigramas. Lisboa: Edições 70, 2001. v. 3.

MARCIAL. Epigrams. Edição e tradução de D. R. Shackleton Bailey. (Loeb Classical Library.) Cambridge, MA; London: Harvard University Press, 1993. v. 2.

NEWLANDS, Carole. Statius' Silvae and the Poetics of Empire. Cambridge, UK: Cambridge University Press, 2002.

PARRA, Amanda Giacon. As religiões em Roma no principado: Petrônio e Marcial. 2010. 148 p. Dissertação (Mestrado em História) - Departamento de História, Universidade Estadual Paulista, Faculdade de Ciências e Letras de Assis, Assis, 2010.

PEDERZANI, Ombretto. L'imperatore e l'eunuco: note di comento a Stat. Silv. 3,4. Athenaeum, Pavia, v. 80, n.1, p. 79-95, 1992.

RIBEIRO JUNIOR, Benedito Inácio. Estudos queer e antiguidade: o caso dos galli de Cibele representados por Marcial. In: CICLO DE ESTUDOS ANTIGOS E MEDIEVAIS, 10.; JORNADA DE ESTUDOS ANTIGOS E MEDIEVAIS, 13.; JORNADA INTERNACIONAL DE ESTUDOS ANTIGOS E MEDIEVAIS, 5., 2014, Londrina. Anais [...]. Londrina, UEL, 2014. p. 75-88.

RIBEIRO JUNIOR, Benedito Inácio. Para além da heteronormatividade: uma análise dos eunucos representados por Estácio, Marcial e Suetônio (Roma, 80-121 d. C). 2016. 196 p. Dissertação (Mestrado em História) - Departamento de História, Universidade Estadual Paulista, Faculdade de Ciências e Letras de Assis, Assis, 2016.

STATIUS, P. P. Silvae. Edição e tradução de D. R. Shackleton Bailey. (Loeb Classical Library.) Cambridge, MA; London: Harvard University Press, 2003.

STATIUS, P. P. Silvae. New York: Oxford University Press, 1990.

SUETÔNIO. A vida dos doze césares. Tradução de Safady-Garibaldi. 3. ed. São Paulo: Athena, 1959.

SULLIVAN, J. P. Martial: The Unexpected Classic - A Literary and Historical Study. Cambridge: Cambridge University Press, 1991.

VESSEY, David. Statius and the Thebaid. London: Cambridge University Press, 1973.

VEYNE, Paul. Sexo e poder em Roma. Tradução de Marcos de Castro. Rio de Janeiro: Civilização Brasileira, 2008. 
VOUT, Caroline. Power and Eroticism in Imperial Rome. Cambridge: Cambridge University Press, 2007.

WILLIAMS, Craig Arthur. Roman Homosexuality: Ideologies of Masculinity in Classical Antiquity. 2. ed. New York: Oxford University Press, 2010.

\title{
NOTAS
}

\begin{abstract}
AUTORIA
Benedito Inácio Ribeiro Junior: Mestre. Professor Assistente I, Faculdade de Administração de Santa Cruz do Rio Pardo, Santa Cruz do Rio Pardo, SP, Brasil. Doutorando, Universidade Estadual Paulista em Assis, Faculdade de Ciências e Letras de Assis, Departamento de História, Assis, SP, Brasil.
\end{abstract}

\section{ENDEREÇO PARA CORRESPONDÊNCIA}

Av. Otto Ribeiro, 1754, apart. 201, 19800-300, Assis, SP, Brasil.

\section{ORIGEM DO ARTIGO}

Extraído da dissertação - Para além da heteronormatividade: uma análise dos eunucos representados por Estácio, Marcial e Suetônio (80-121 d.C.), apresentada ao Programa de Pós-graduação em História da Universidade Estadual Paulista em Assis, em 2016. As ideias aqui apresentadas também são resultado de um estágio de pesquisa realizado na Faculty of Classics da Universidade de Cambridge, no Reino Unido, sob a supervisão de Christopher Lyall Whitton.

\section{AGRADECIMENTOS}

Agradeço à Fundação de Amparo à Pesquisa do Estado de São Paulo (FAPESP), que financiou a pesquisa que deu origem a este artigo. Sou grato também ao professor Chris Whitton, que orientou a minha pesquisa nos quatro meses que estive na Universidade de Cambridge e que me ensinou um pouco mais sobre a academia e a vida na Inglaterra. Por fim, agradeço ao Núcleo de Estudos Antigos e Medievais da UNESP - Assis (NEAM) e a todos os seus integrantes, que debateram incansavelmente a minha pesquisa de mestrado, em especial, à minha orientadora Dra. Andrea Lúcia Dorini de Oliveira Carvalho Rossi.

\section{FINANCIAMENTO}

Este artigo foi financiado com bolsa de mestrado da Fundação de Amparo à Pesquisa do Estado de São Paulo (FAPESP), processo 2013/26304-6, e com Bolsa de Estágio e Pesquisa no Exterior (BEPE) da FAPESP, processo 2015/00869-2.

\section{APROVAÇÃO DE COMITÊ DE ÉTICA EM PESQUISA \\ Não se aplica.}

\section{CONFLITO DE INTERESSES}

Não houve conflito de interesse.

\section{LICENÇA DE USO}

Este artigo está licenciado sob a Licença Creative Commons CC-BY. Com essa licença você pode compartilhar, adaptar, criar para qualquer fim, desde que atribua a autoria da obra.

\section{PUBLISHER}

Universidade Federal de Santa Catarina. Programa de Pós-Graduação em História. Portal de Periódicos UFSC. As ideias expressadas neste artigo são de responsabilidade de seus autores, não representando, necessariamente, a opinião dos editores ou da universidade. 


\section{EDITORES}

Alex Degan

Beatriz Mamigonian

Fábio Augusto Morales

Flávia Florentino Varella (Editora-chefe)

Tiago Kramer de Oliveira

Waldomiro Lourenço da Silva Júnior

\section{HISTÓRICO}

Recebido em: 3 de julho de 2018

Aprovado em: 10 de dezembro de 2018

Como citar: RIBEIRO JUNIOR, Benedito Inácio. Uma sílaba rebelde no coração do Império: tensões políticas e de gênero no principado de Domiciano. Esboços, Florianópolis, v. 26, n. 42, p. 378-403, maio/ago. 2019. 